\title{
Guia ilustrado da morfologia do tecido uretral de ratas
}

\author{
Fernanda Piculo \\ Gabriela Marini \\ Débora Cristina Damasceno \\ Yuri Karen Sinzato \\ Angélica Mércia Pascon Barbosa \\ Selma Maria Michelin Matheus \\ Marilza Vieira Cunha Rudge
}

\author{
Sérgio Luis Felisbino \\ Jaqueline Rinaldi \\ Flávia Karina Delella \\ Sérgio Alexandre Alcântara do Santos \\ Talísia Moreto \\ Gelson Rodrigues \\ (collab.)
}

\section{SciELO Books / SciELO Livros / SciELO Libros}

SANTOS, SL., et al., corp. aut. PICULO, F. et al. Guia ilustrado da morfologia do tecido uretral de ratas [online]. São Paulo: Editora UNESP, 2014, 44 p. ISBN 978-85-68334-51-5. Available from SciELO Books $<$ http://books.scielo.org $>$.

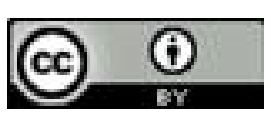

All the contents of this work, except where otherwise noted, is licensed under a Creative Commons Attribution 4.0 International license.

Todo o conteúdo deste trabalho, exceto quando houver ressalva, é publicado sob a licença Creative Commons Atribição $\underline{4.0}$.

Todo el contenido de esta obra, excepto donde se indique lo contrario, está bajo licencia de la licencia Creative Commons $\underline{\text { Reconocimento } 4.0 .}$. 


\section{Guia ilustrado DA MORFOLOGIA DO TECIDO URETRAL DE RATAS}




\title{
FUNDAÇÃO EDITORA DA UNESP
}

\author{
Presidente do Conselho Curador \\ Mário Sérgio Vasconcelos \\ Diretor-Presidente \\ José Castilho Marques Neto \\ Editor-Executivo \\ Jézio Hernani Bomfim Gutierre
}

Superintendente Administrativo e Financeiro

William de Souza Agostinho

Assessores Editoriais

João Luís Ceccantini

Maria Candida Soares Del Masso

Conselho Editorial Acadêmico

Áureo Busetto

Carlos Magno Castelo Branco Fortaleza

Elisabete Maniglia

Henrique Nunes de Oliveira

João Francisco Galera Monico

José Leonardo do Nascimento

Lourenço Chacon Jurado Filho

Maria de Lourdes Ortiz Gandini Baldan

Paula da Cruz Landim

Rogério Rosenfeld

Editores-Assistentes

Anderson Nobara

Jorge Pereira Filho

Leandro Rodrigues 
FERNANDA PICULO

GABRIELA MARINI

DÉBORA GRISTINA DAMASCENO

YURI KAREN SINZATO

ANGÉLICA MÉRCIA PASCON BARBOSA SELMA MARIA MICHELIN MATHEUS MARILZA VIEIRA CUNHA RUDGE

\title{
Guia ilustrado DA MORFOLOGIA DO TECIDO URETRAL DE RATAS
}

\author{
Colaboradores \\ Sérgio Luis Felisbino \\ Jaqueline Rinaldi \\ Flávia Karina Delella \\ Sérgio Alexandre Alcântara do Santos \\ Talísia Moreto \\ Gelson Rodrigues
}


Direitos de publicação reservados à:

Fundação Editora da Unesp (FEU)

Praça da Sé, 108

$$
\begin{gathered}
\text { 01001-900 - São Paulo - SP } \\
\text { Tel.: (0xx11) 3242-7171 } \\
\text { Fax: (0xx11) 3242-7172 } \\
\text { www.editoraunesp.com.br } \\
\text { www.livrariaunesp.com.br } \\
\text { feu@editora.unesp.br }
\end{gathered}
$$

Cip - Brasil. Catalogação na publicação

Sindicato Nacional dos Editores de Livros, RJ

G971

Guia ilustrado da morfologia do tecido uretral de ratas / Fernanda Piculo et al.; colaboração Sérgio Luis Felisbino et al. São Paulo: Editora Unesp Digital, 2015.

Recurso digital: il.

Formato: ePDF

Requisitos do sistema: Adobe Acrobat Reader

Modo de acesso: World Wide Web

ISBN 978-85-68334-51-5 (recurso eletrônico)

1. Morfologia-Animais. 2. Livros eletrônicos. I. Piculo, Fernanda. II. Felisbino, Sérgio Luis. III. Título.

15-20312

CDD: 591.3

CDU: 591

Este livro é publicado pelo projeto Edição de Textos de Docentes e Pós-Graduados da UNESP - Pró-Reitoria de Pós-Graduação da UNESP (PROPG) / Fundação Editora da Unesp (FEU)

Editora afiliada:

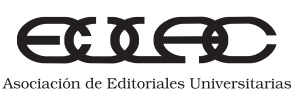
Asociación de Editoriales Universitarias
de América Latina y el Caribe

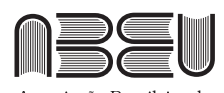

Associação Brasileira de Editoras Universitárias 


\begin{abstract}
Nossos agradecimentos
a Talísia Moreto, assistente de suporte acadêmico do Laboratório de Pesquisa Experimental de Ginecologia, Obstetrícia e Mastologia, pelos cuidados prestados aos animais e pelo auxílio durante a realização dos trabalhos científicos;

a Gelson Rodrigues, técnico do departamento de Anatomia da Unesp, pelo apoio, pela disponibilidade e pela atenção dedicados ao processamento do material de histologia;

ao Centro de Microscopia Eletrônica pela acolhida e pela concessão das dependências durante a realização deste trabalho;

aos animais de laboratório, que involuntariamente cederam suas vidas para o estudo da ciência e proporcionaram avanços no conhecimento científico; à Fundação de Amparo à Pesquisa do Estado de São Paulo (Fapesp), pelo auxílio financeiro.
\end{abstract}


A todos que contribuíram, direta ou indiretamente, na execução dos trabalhos para obtenção e processamento do material utilizado para as ilustrações deste livro. 


\title{
SUMÁRIO
}

\author{
Apresentação 9 \\ Introdução 11 \\ 1 Metodologia e equipamentos 13 \\ 2 Imunoistoquímica 27 \\ 3 Morfologia da uretra 31
}

Referências 41 


\section{ApresentaÇão}

O grupo de pesquisa acadêmico "Diabete e Gravidez - Clínico e Experimental" da Faculdade de Medicina da Unesp, campus de Botucatu, ${ }^{1}$ tem estudado de forma translacional os aspectos da hiperglicemia gestacional relacionada à incontinência urinária no sexo feminino e também em modelos animais. Os resultados desse estudo ajudam a elucidar os mecanismos fisiopatológicos que conduzem a distúrbios do assoalho pélvico feminino. Dessa forma, diversas pesquisas estão sendo realizadas na

1 Fazem parte desse grupo as autoras Fernanda Piculo, Gabriela Marini, Débora Cristina Damasceno, Yuri Karen Sinzato, Angélica Mércia Pascon Barbosa, Marilza Vieira Cunha Rudge (Laboratório de Pesquisa Experimental em Ginecologia, Obstetrícia e Mastologia do Departamento de Ginecologia e Obstetrícia) e Selma Maria Michelin Matheus (Departamento de Anatomia do Instituto de Biociências da Unesp). Integram ainda o grupo os colaboradores Talísia Moreto (Laboratório de Pesquisa Experimental em Ginecologia, Obstetrícia e Mastologia do Departamento de Ginecologia e Obstetrícia), Sérgio Luis Felisbino, Jaqueline Rinaldi, Flávia Karina Delella, Sérgio Alexandre Alcântara do Santos (Departamento de Morfologia do Instituto de Biociências da Unesp) e Gelson Rodrigues (Departamento de Anatomia do Instituto de Biociências da Unesp). 
tentativa de ampliar a compreensão dos fenômenos que resultarão no melhor atendimento às pacientes.

A estratégia do grupo para iniciar a pesquisa translacional em modelos animais para testar hipóteses sobre os mecanismos de continência urinária foi dada pela similaridade da distribuição normal da musculatura estriada e da neuroanatomia da uretra em mulheres e em ratas. $\mathrm{O}$ modelo animal permite controlar variáveis que não são possíveis em humanos, além de possibilitar análises que são eticamente inviáveis em estudos clínicos.

Este guia ilustrado da morfologia do tecido uretral de ratas surgiu como iniciativa deste grupo de pesquisa, após estudo experimental, realizado em 2011, das alterações morfológicas das fibras musculares estriadas tipos I e II da uretra de ratas prenhes diabéticas. Desde então, houve a necessidade de elaboração deste material didático, a fim de padronizar, facilitar e aprimorar os estudos posteriores e proporcionar aos estudantes e pesquisadores das áreas biológicas e da saúde acervo de imagens e informações que auxilie no estudo da morfologia tanto específica para o tecido uretral, como possivelmente no estudo morfológico e metodológico de outros tecidos. 


\section{INTRODUÇÃO}

\section{Histórico}

A necessidade de elaboração deste material pelo grupo de pesquisa acadêmico "Diabete e Gravidez - Clínico e Experimental" da Faculdade de Medicina da Unesp, campus de Botucatu, surgiu após estudo experimental realizado por Marini et al. (2011), que avaliou as alterações morfológicas das fibras musculares estriadas tipos I e II da uretra de ratas prenhes diabéticas. Esse estudo encontrou diversas dificuldades relacionadas tanto ao conhecimento anatômico e histológico da uretra quanto à metodologia utilizada: 1) a dissecção da uretra de forma isolada levou à grande perda tecidual, indicando a necessidade de retirá-la em conjunto com a vagina, o que possibilitou melhor análise; 2) a falta de padronização na forma de congelamento e armazenamento dos materiais resultou na degradação tecidual e no aparecimento de artefatos histológicos que interferiram na interpretação dos resultados; 3) o uso de cortes transversais aleatórios seccionados em criostato não permitiu a identificação de um padrão histológico que pudesse ser utilizado para todas as uretras, o que foi 
possível somente após a análise de cortes seriados que evidenciaram a região média da uretra como o local de maior quantidade e de melhor visualização de fibras musculares estriadas; 4) dificuldade na padronização do tempo utilizado nas etapas das reações imunoistoquímicas e da melhor diluição dos anticorpos para fibras rápidas e lentas.

Diante da necessidade de aprofundar o conhecimento das alterações encontradas na uretra de ratas prenhes diabéticas e de melhor direcionamento dos estudos relacionados ao trato urinário inferior, tornou-se primordial a elaboração de material-base que ilustrasse as estruturas anatômicas e morfológicas gerais da uretra, bem como descrevesse detalhadamente as metodologias empregadas para assim possibilitar o melhor entendimento dos mecanismos que levam às alterações nos componentes estruturais da uretra, além de servir como modelo para estudos posteriores.

\section{Objetivo}

O objetivo deste guia ilustrado é ser fonte de consulta que facilite o entendimento das estruturas que compõem a uretra e subsidiar a execução de técnicas morfológicas em modelos experimentais. Essa obra será útil para alunos de graduação e pós-graduação em treinamento na pesquisa experimental, bem como para pesquisadores envolvidos na área de uroginecologia e obstetrícia. 


\section{1 \\ Metodologia e equipamentos}

\section{Métodos histológicos para avaliação dos componentes uretrais de ratas}

\section{Microscopia Fotônica Convencional}

A correta observação do material biológico em microscopia óptica implica uma série de procedimentos técnicos prévios, que a seguir se descrevem sumariamente. Esses procedimentos designam-se genericamente por técnicas histológicas.

A técnica histológica visa à preparação dos tecidos destinados ao estudo à microscopia de luz. O exame ao microscópio é feito geralmente por luz transmitida, o que significa que a luz deve atravessar o objeto a ser examinado. Assim, é necessária a obtenção de fragmentos dos tecidos que serão coletados em lâminas muito finas e transparentes.

\section{Fixação do tecido}

Tem por finalidade conservar os tecidos com o aspecto mais próximo possível do material vivo. O fixador mais frequentemente utilizado é o Formol a 10\%. O órgão 
é submerso em formol e, dependendo da densidade do tecido, do seu tamanho e da temperatura ambiente, a fixação pode ser mais rápida ou mais lenta. Esses fragmentos são então acondicionados em pequenas caixas perfuradas de plástico (cassetes) com a identificação do material (Figura 1A).

\section{Processamento em parafina e inclusão}

Tem por finalidade retirar a água do tecido e substituí-la por parafina, o que torna o tecido mais firme e, portanto, passível de ser cortado em fatias delgadas (4 a 10 $\mu \mathrm{m})$. Isso é feito pela imersão dos cassetes em banhos sucessivos de álcool (que retira a água, mas não se mistura com parafina), de xilol (que se mistura tanto com o álcool quanto com a parafina) e finalmente de parafina aquecida (entre 55 e $60^{\circ} \mathrm{C}$ ). Dessa forma, toda a água do tecido é retirada e substituída por parafina (Figura1B). O tecido parafinizado é incluído em um pequeno bloco de parafina (Figura 1C), com a sua identificação, e posteriormente é submetido à microtomia.

\section{Microtomia e montagem de lâminas}

Consiste em cortar o bloco de parafina em fatias muito delgadas. O micrótomo (Figura 1D) apresenta um componente que mantém o bloco firmemente preso e alinhado (braço) e outro mecanismo que movimenta o braço ao qual o bloco está preso. Esse movimento consiste em um movimento de subida e descida e em outro de avanço. Cada vez que o braço contendo o bloco completa um curso, o bloco é submetido à face afiada de uma navalha de aço e uma fatia delgada de parafina contendo tecido é cortada (Figura 1E). Estes cortes são então colocados em banho-maria histológico, que contém água aquecida, com a finalidade de distendê-los e, em seguida, os mesmos são colocados em lâminas histológicas (Figura 1F). 
Figura 1 - Etapas da microscopia fotônica convencional
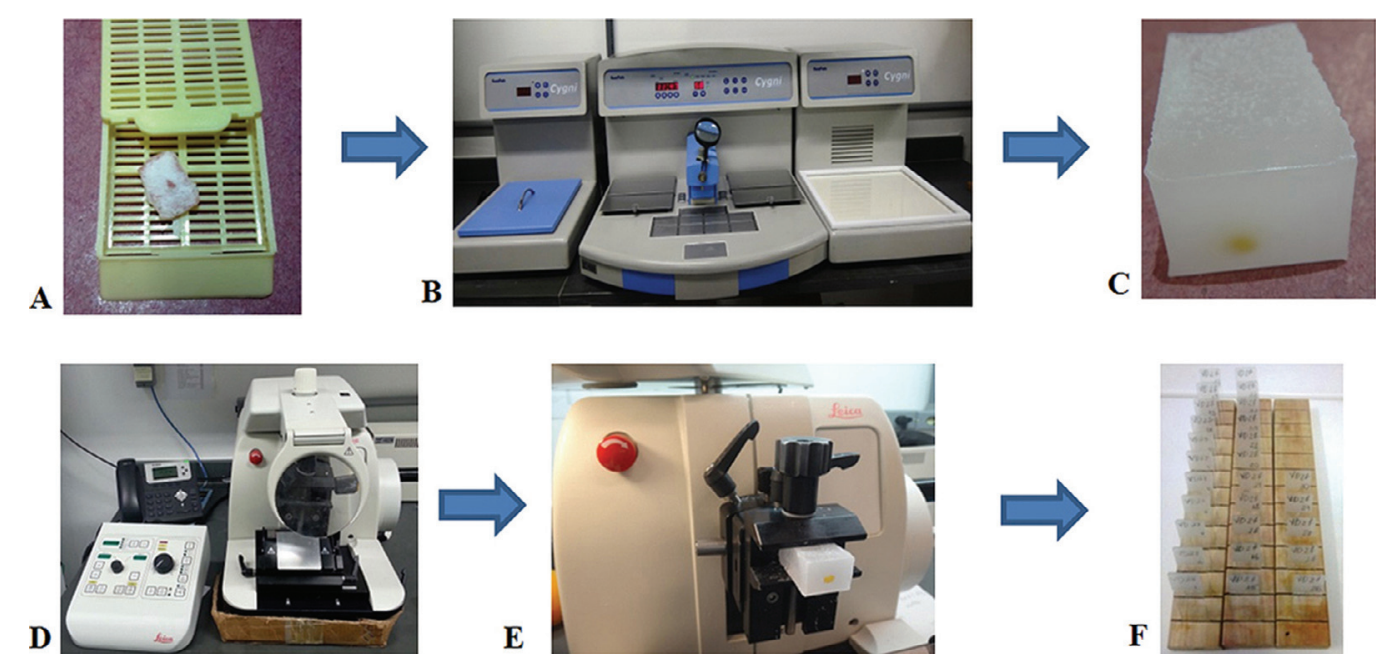

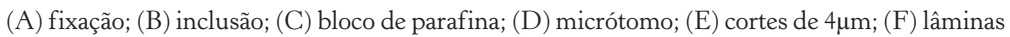




\section{Desparafinização}

Antes da coloração das lâminas, há necessidade de se retirar a parafina na qual os cortes encontram-se incluídos. Para isso, os cortes são submetidos a sucessivos banhos em xilol. Em seguida são submetidos a banhos em álcool, em concentração decrescente, até serem hidratados. Para observação dos cortes histológicos, há necessidade de corá-los com corantes específicos de acordo com o objetivo do estudo.

\section{Coloração}

A coloração consiste em etapa muito importante para a visualização das estruturas do tecido. Normalmente são utilizados corantes hidrossolúveis, sendo necessária, desse modo, a remoção da parafina do material que foi preparado nas etapas descritas anteriormente e que permanece na lâmina de vidro.

Existem muitos tipos de corantes, mas de um modo geral podem ser agrupados em três classes distintas:

1) corantes que diferenciam os componentes ácidos e básicos das células;

2) corantes especializados que diferenciam os componentes fibrosos da matriz extracelular;

3) sais metálicos que precipitam nos tecidos.

- Corantes basófilos (hematoxilina, azul de toluidina, azul de metileno e azul de alcian): comportam-se como cátions e tem caráter básico. De modo geral, as células e tecidos dos cortes que contêm muitos grupos ácidos tem afinidade por esses corantes e se coram em azul arroxeado. Os núcleos têm grupamentos ácidos nos seus ácidos nucleicos e, por isso, são basófilos e se coram em roxo pela hematoxilina. 
- Corantes acidófilos ou eosinófilos (eosina e corantes semelhantes à eosina): comportam-se como ânions e tem caráter ácido. De modo geral, as células e tecidos dos cortes que contêm muitos grupos básicos têm afinidade com esses corantes e se coram em rosa. As proteínas de modo geral, o citoplasma e as mitocôndrias se coram preferencialmente pelos corantes ácidos. A matriz extracelular da maioria dos tecidos, que é muito rica em colágeno, cora-se em rosa pela eosina.

Os corantes mais utilizados nos procedimentos histológicos são a hematoxilina e a eosina (HE) (Figura 2).

Figura 2 - Micrografia do corte transversal da uretra de ratas corada com $\mathrm{HE}$, evidenciando o citoplasma em rosa e o núcleo em roxo

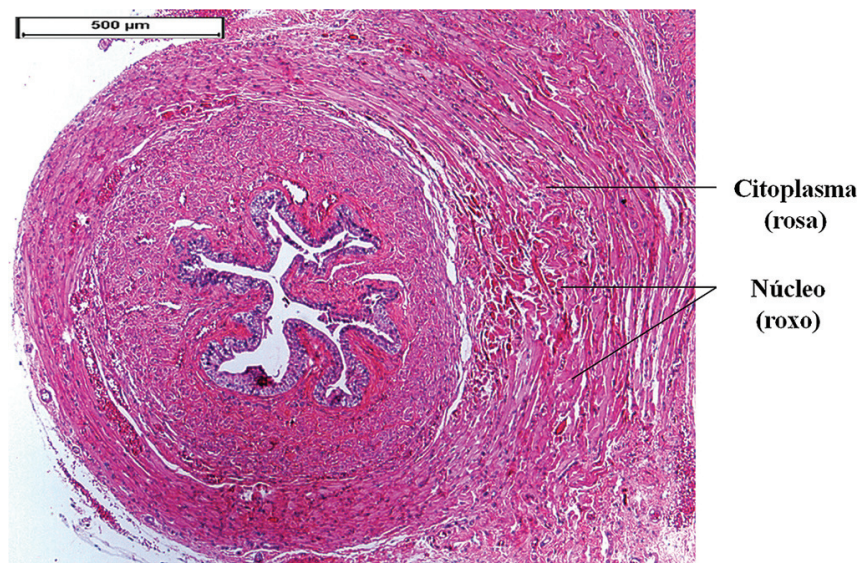

Aumento de $4 \mathrm{x}$

Outros corantes são também utilizados em procedimentos de rotina em laboratórios, tais como:

- corantes tricrômicos (Tricrômico de Masson): são utilizados para evidenciar determinadas estruturas celulares, como análise geral simultânea das fibras musculares lisas e estriadas (coradas em vermelho) e das fibras colágenas (coradas em azul). 
Figura 3 - Micrografia do corte transversal da uretra de ratas corada com Tricrômico de Masson, evidenciando as fibras musculares lisas e estriadas (em vermelho) e fibras colágenas (em azul)

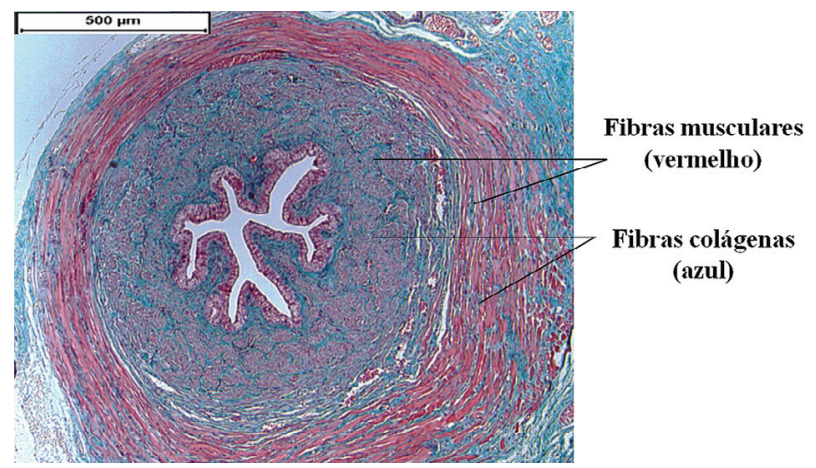

Aumento de $4 \mathrm{x}$

- Picrosirius Red: constitui uma solução saturada de ácido pícrico para análise das fibras de colágeno tipo I e tipo III simultaneamente.

Figura 4 - Micrografia do corte transversal da uretra de ratas corada com Picrosirius Red, evidenciando as fibras de colágeno tipo I e III em vermelho

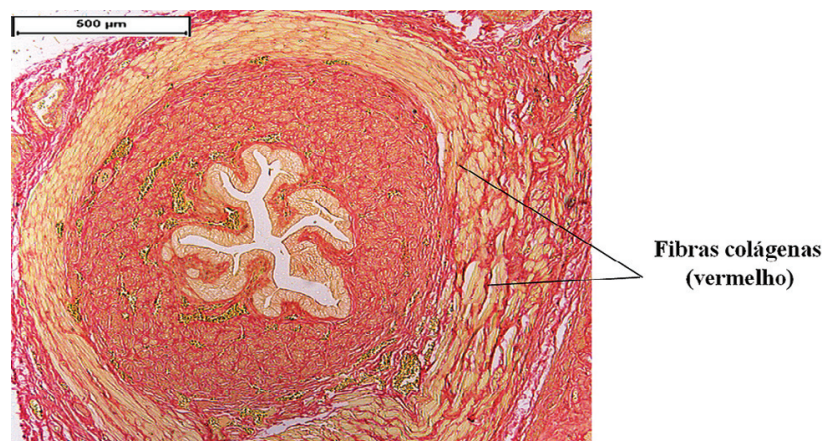

Aumento de $4 \mathrm{x}$

- Reticulina de Gomori: permite análise das fibras de colágeno tipo I (coradas em dourado) e tipo III (impregnadas pela prata e coradas em preto) separadamente. 
Figura 5 - Micrografia do corte transversal da uretra de ratas corada com Reticulina de Gomori, evidenciando as fibras de colágeno tipo I (dourado) e III (preto)

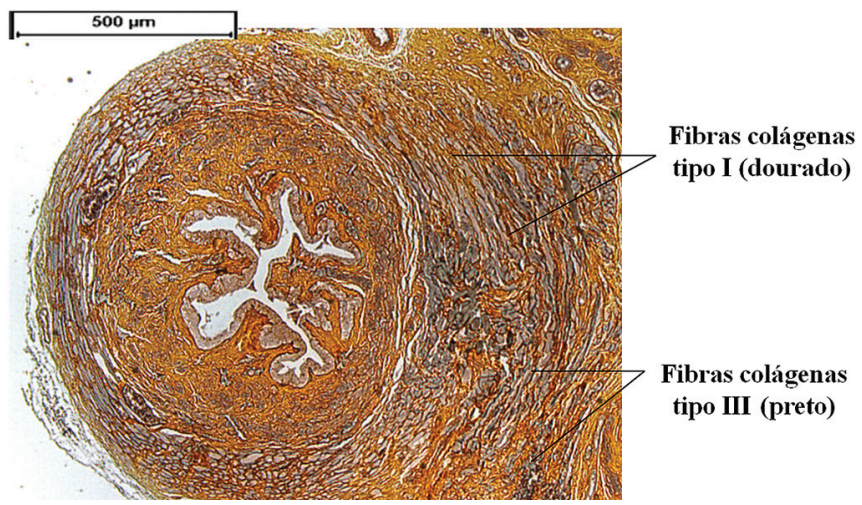

Aumento de $4 \mathrm{x}$

- Ácido Periódico de Schiff (PAS): estruturas ricas em carboidratos assumem coloração magenta (violeta/avermelhada) após serem submetidas ao PAS.

Figura 6 - Micrografia do corte transversal da uretra de ratas corada com PAS, evidenciando glicídios (em magenta)

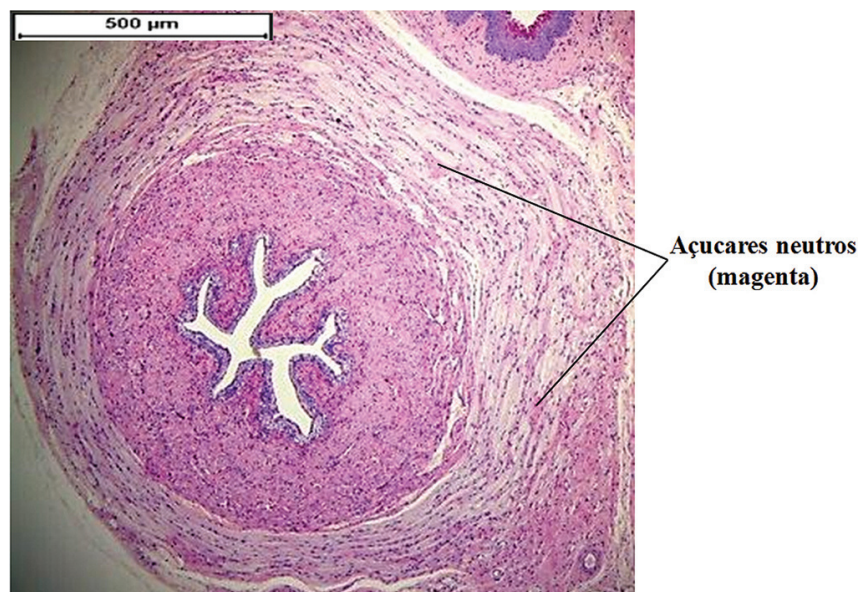

Aumento de $4 \mathrm{x}$ 
- Azul de Toluidina: corante básico que tinge substratos com grupamentos ácidos como carboxila e sulfato presentes nos polissacarídeos ácidos, ácido hialurônico e condroitino sulfato.

Figura 7 - Micrografia do corte transversal da uretra de ratas corada com Azul de Toluidina, evidenciando os núcleos em azul arroxeado

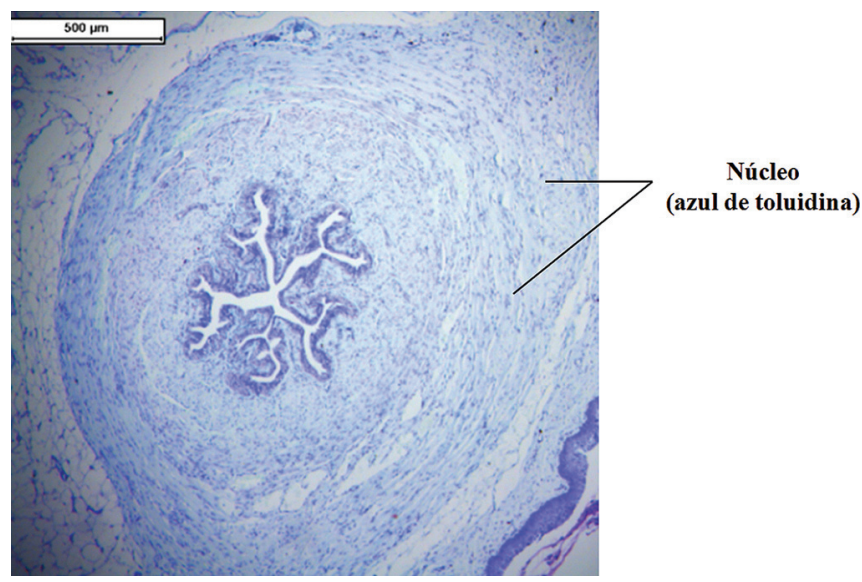

Aumento de 4x

\section{Análise em microscópio fotônico convencional}

Após a coloração, as lâminas são analisadas em microscópio fotônico comum (Figura 8). O microscópio fotônico comum, também designado por microscópio de câmara clara, é um sistema óptico capaz de fornecer uma imagem ampliada de um objeto, permitindo a observação de detalhes invisíveis a olho nu. É constituído basicamente por dois conjuntos de lentes: o conjunto objetiva e o conjunto ocular. A ampliação é uma das características ópticas essenciais da objetiva. A ocular, por sua vez, fornece uma imagem virtual mais afastada, mas que, através do cristalino, projeta-se na retina do globo ocular. Entre 
outras características nos microscópios, destacam-se três principais: a ampliação, a abertura numérica e o poder de resolução. A ampliação do microscópio é determinada a partir das ampliações da objetiva e da ocular. Habitualmente, os microscópios são equipados com diversas objetivas montadas sobre um tambor rotativo (ou revólver), o que permite mudar comodamente de ampliação no curso do trabalho. As lentes oculares mais comuns oferecem uma ampliação de 10x, e as objetivas de maior ampliação, de 100x. A ampliação máxima habitual do microscópio fotônico raramente ultrapassa o limiar útil de 1000x .

Figura 8 - Microscópio fotônico convencional

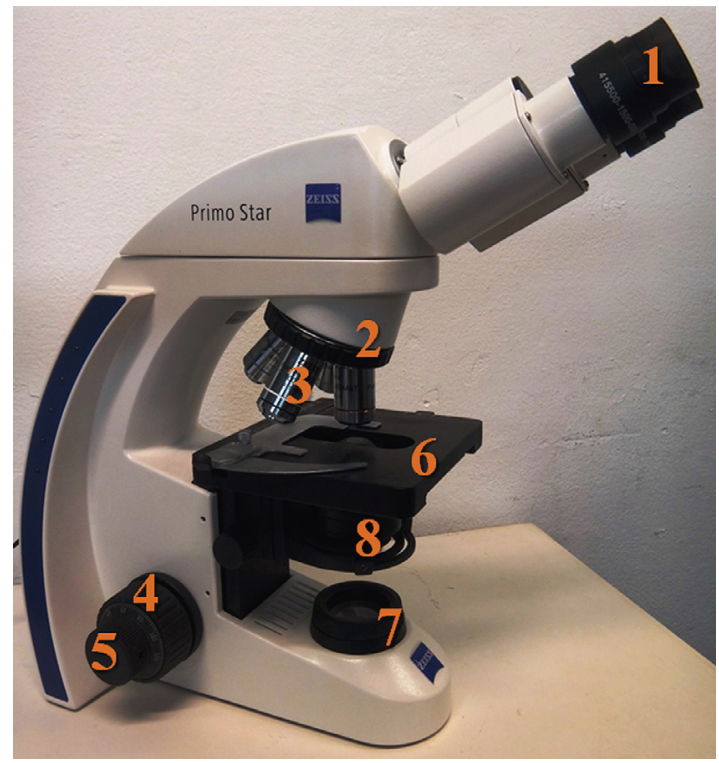

(1) lente ocular; (2) revólver das objetivas; (3) objetiva; (4) parafuso macrométrico para focalização da imagem; (5) parafuso micrométrico para focalização da imagem; (6) mesa (sobre a qual a lâmina é colocada); (7) fonte de luz; (8) diafragma e condensador 


\section{Microscopia eletrônica de transmissão}

O desenvolvimento concomitante da microscopia eletrônica e da melhoria nas técnicas de preparação dos tecidos ampliaram consideravelmente o campo de estudo da histologia, pois o microscópio eletrônico é aproximadamente 1000 vezes mais poderoso que o microscópio óptico convencional. O alto poder de resolução e de ampliação do microscópio eletrônico de transmissão permite a obtenção de imagens com uma grande riqueza de detalhes.

\section{Fixação do tecido}

O tecido é fixado por perfusão e/ou imersão. No caso específico deste estudo, a uretra deve ser removida isoladamente da parede vaginal (Figura 9A) e, em seguida, fixada inicialmente em solução de Karnovisky. Após a fixação inicial, o tecido é dissecado e suas extremidades são reduzidas. Se necessário, utiliza-se reagente específico para intensificar a ultraestrutura a ser analisada de acordo com o objetivo do estudo.

\section{Processamento}

O fragmento geralmente é embebido em tetróxido de ósmio, depois passa por processos de lavagens, desidratação em concentrações crescentes de álcool e imersão em resina (Figura 9B), na qual permanece até a polimerização. $\mathrm{O}$ excesso de resina polimerizada é retirado para expor o material de estudo (Figura 9C) e permitir o seu fatiamento no ultramicrótomo (Figura 9D).

\section{Ultramicrotomia e montagem das telas}

Ultramicrotomia é um método para o corte de espécimes em fatias ou seções extremamente finas, que podem ser vistas em um microscópio eletrônico de transmissão 
(MET). As seções devem ser finas porque os elétrons de 50 a $125 \mathrm{kV}$ dos microscópios eletrônicos padrão não podem passar através de material biológico mais espesso que $150 \mathrm{~nm}$. Para melhores resoluções, as seções devem ser de 30 a $60 \mathrm{~nm}$. O equipamento que realiza a ultramicrotomia é chamado de ultramicrótomo, sendo que a própria operação de corte é supervisionada e controlada utilizando-se um microscópio óptico incorporado ao aparelho.

Existem muitos equipamentos envolvidos no processo de ultramicrotomia. Seções ditas "finas", ou seja, seções de 50 a $100 \mathrm{~nm}$ de espessura, podem ser visualizadas no MET. Uma pequena amostra é retirada do espécime a ser investigado. Uma área é escolhida para ser seccionada para o MET e a face do bloco é reaparada a um tamanho não maior que $0,7 \mathrm{~mm}$ em um lado. As fases do bloco normalmente têm forma de quadrado, retângulo, trapézio ou triângulo. Finalmente, cortes finos são feitos por uma lâmina chamada de "faca" de vidro ou diamante, usando um ultramicrótomo e as seções ficam flutuando na água em uma cuba ou calha no equipamento. As seções são então recuperadas da superfície da água e montadas sobre uma tela ou uma grade de cobre, níquel, ouro ou outro metal (Figura 9E) e são contracoradas geralmente com uranila e chumbo. 
Figura 9 - Fases do processamento do material para microscopia eletrônica de transmissão.

A
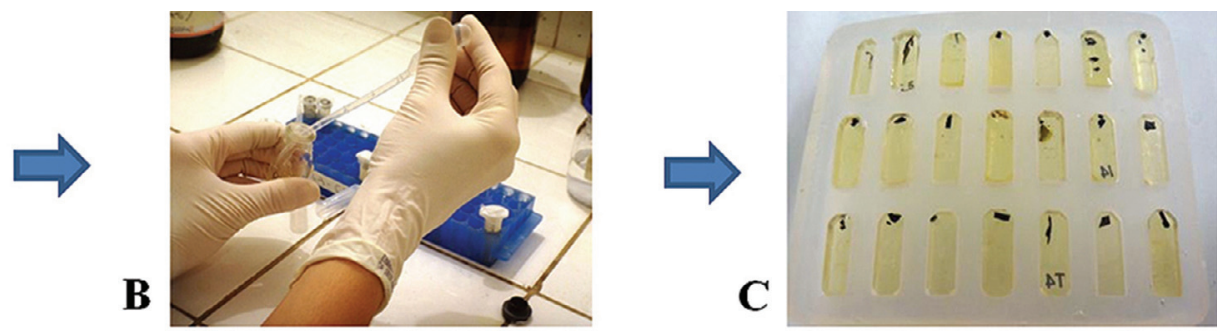

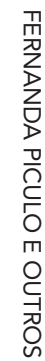

D
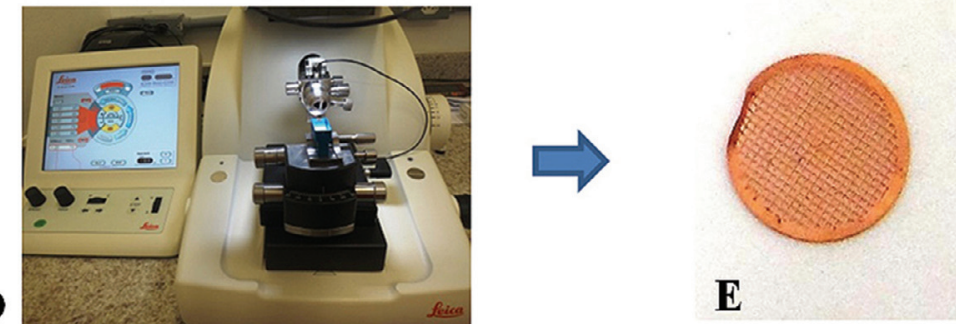

(A) uretra isolada; (B) infiltração em resina; (C) blocos de resina; (D) ultramicrótomo; (E) tela de cobre 


\section{Análise em microscópio eletrônico de transmissão}

As imagens no microscópio eletrônico de transmissão (Figuras 10 e 11) são formadas pela excitação de uma tela fluorescente ou um filme fotográfico por elétrons. Esses elétrons são produzidos graças ao aquecimento de um filamento no vácuo. Essas partículas são aceleradas por causa de uma diferença de potencial de 60 a $100 \mathrm{Kv}$ existentes entre o cátodo e o ânodo. Esse feixe é defletido por lentes eletromagnéticas, de maneira parecida ao que acontece com a luz no microscópio óptico. O condensador focaliza o feixe de elétrons no plano do objeto, e a objetiva forma sua imagem. Essa imagem é ainda ampliada por uma ou duas lentes que a projetam numa tela fluorescente ou em filme fotográfico.

Simplificadamente, o funcionamento do microscópio eletrônico de transmissão se baseia na propriedade que as estruturas têm de desviar ou deixar passar por si os elétrons. As estruturas que desviam os elétrons são chamadas de elétrons densas e aparecem escuras na imagem, uma vez que os elétrons não chegam até a tela fluorescente. Já as estruturas que são atravessadas pelos elétrons (elétron lúcidas) aparecem claras na imagem, pois os elétrons que incidiram sobre a estrutura conseguem excitar a tela fluorescente ou o filme fotográfico que fica abaixo do corte.

Figura 10 - Trajeto dos elétrons (em amarelo) no microscópio eletrônico de transmissão

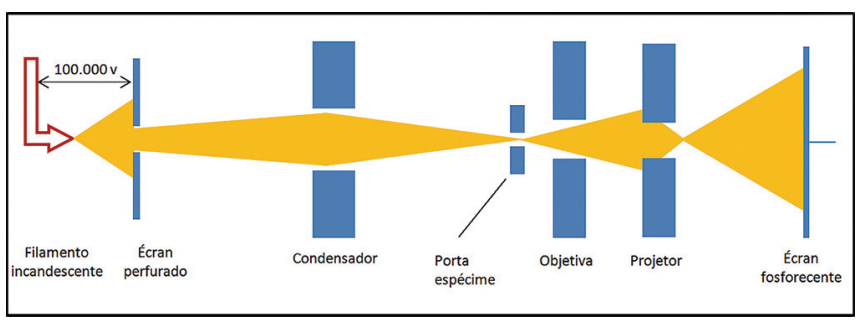


Figura 11 - Microscópio eletrônico de transmissão (MET)

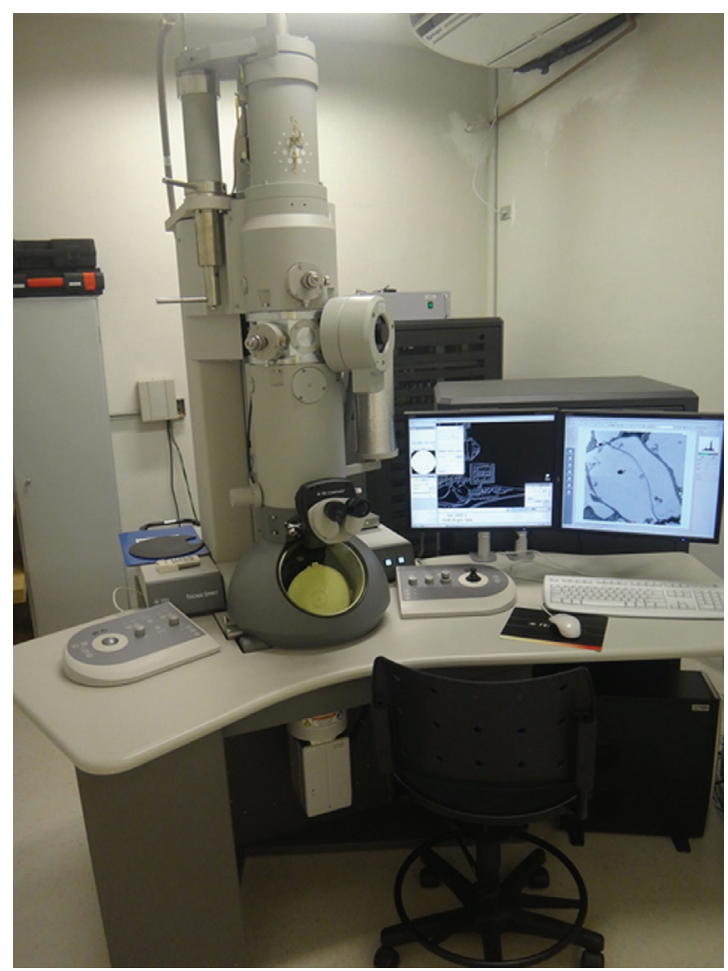




\section{2 \\ IMUNOISTOQUÍMICA}

Nessa técnica, um anticorpo é usado para detectar especificamente um antígeno celular por meio de coloração específica, processo que permite que ele seja prontamente visualizado em microscópio. O material pode ser fixado e incluído em parafina, de forma similar à microscopia fotônica convencional, ou pode ser envolvido em talco, congelado em nitrogênio líquido (Figura 12A) e armazenado em freezer a $-80^{\circ} \mathrm{C}$ (Figura 12B) para posterior obtenção dos cortes histológicos em criostato (Figura 12C). Nesse caso, as lâminas (Figura 12D) devem ser alocadas preferencialmente em laminário com sílica gel (Figura 12E) e posteriormente envolvidas em parafilm (Figura 12F) para evitar hidratação dos cortes. 
Figura 12 - Fases do processamento do material para imunoistoquímica de fibras rápidas e lentas
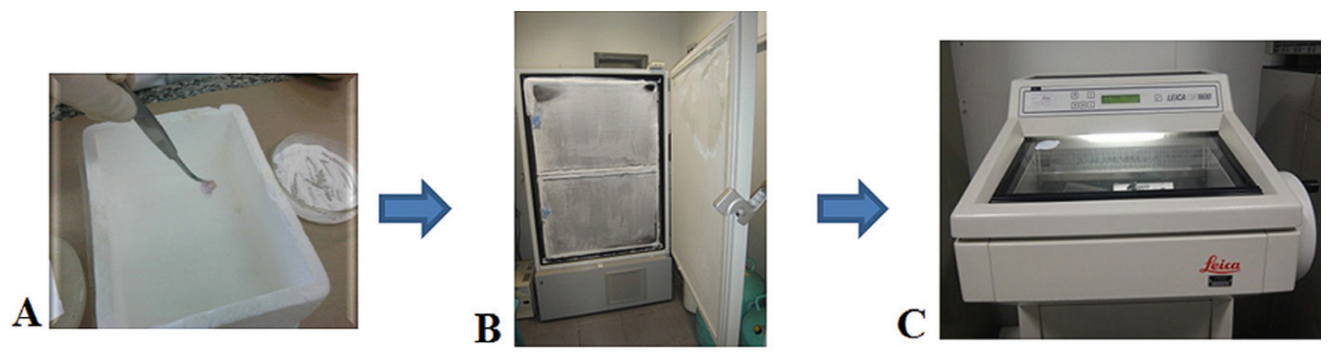

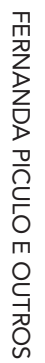

D
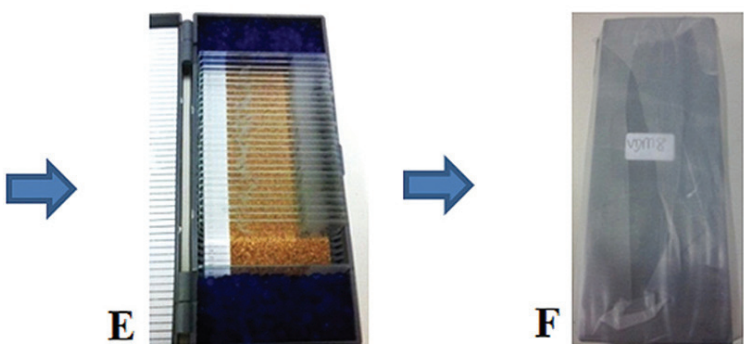

(A) talco nitrogênio líquido; (B) freezer $-80^{\circ} \mathrm{C}$; (C) criostato: cortes $6 \mu \mathrm{m}$; (D) lâminas; (E) sílica gel; (F) parafilm 


\section{Protocolo específico para imunomarcação de fibras musculares lentas e rápidas}

As lâminas obtidas são submetidas ao método de imunoperoxidase StreptABComplex/HRP por meio da utilização de anticorpos comerciais primários específicos para cada proteína do estudo, como descrito a seguir:

\begin{tabular}{|l|c|c|c|}
\hline Anticorpo monoclonal & Clone & Empresa & Diluição \\
\hline Anti-miosina rápida & WB-MYHCf & Novocastra & $1: 160$ \\
\hline Anti-miosina lenta & WB-MYHCs & Novocastra & $1: 120$ \\
\hline
\end{tabular}

Os cortes são fixados com acetona gelada e lavados, e depois ocorre o bloqueio da peroxidade endógena com peróxido de hidrogênio $\left(\mathrm{H}_{2} \mathrm{O}_{2}\right) 3 \%$ em metanol. Os cortes são lavados novamente e é feito o bloqueio de interações proteína-proteína não específicas por solução de albumina bovina a $3 \%$ em PBS por 1 hora a $37^{\circ} \mathrm{C}$. Depois as lâminas são incubadas com anticorpo primário (específico para o antígeno) diluído em solução de albumina bovina a $1 \%$ e ázida sódica a $0,1 \%$ em PBS, em câmara úmida, durante uma hora a $37^{\circ} \mathrm{C}$ e, depois, durante 18 horas (overnight) a $4{ }^{\circ} \mathrm{C}$. Após lavagens com tampão PBS, ocorre incubação com anticorpo secundário (específico para a espécie animal em que será produzido o anticorpo primário), em câmara úmida trinta minutos a $37^{\circ} \mathrm{C}$. Na reação com Complexo Avidina-biotina-peroxidase (ABS), o anticorpo secundário é biotinilado. A revelação é feita com solução de substrato cromogênico contendo diaminobenzidina (Sigma, USA) 0,6\%, peróxido de hidrogênio a $0,06 \%$, dimetilsulfóxido a $1 \%$ em PBS, em banho de 5 minutos em câmara escura e a $37^{\circ} \mathrm{C}$. Os cortes são contracolorados com Hematoxilina de Harris, lavados, desidratados e montados em Entellan (Merck) com lamínulas. 


\section{3 \\ MORFOLOGIA DA URETRA}

\section{Anatomia da uretra de ratas}

A uretra feminina localiza-se imediatamente ventral à vagina e abre-se independentemente dela. Possui aproximadamente $10 \mathrm{~mm}$ de comprimento (Figura 13). O óstio uretral externo localiza-se dorsalmente ao clitóris em uma protusão na forma de cone sob a pele, que também recebe as aberturas das glândulas clitoriais.

Figura 13 - Representação do comprimento da uretra de rata $(\mathrm{cm})$

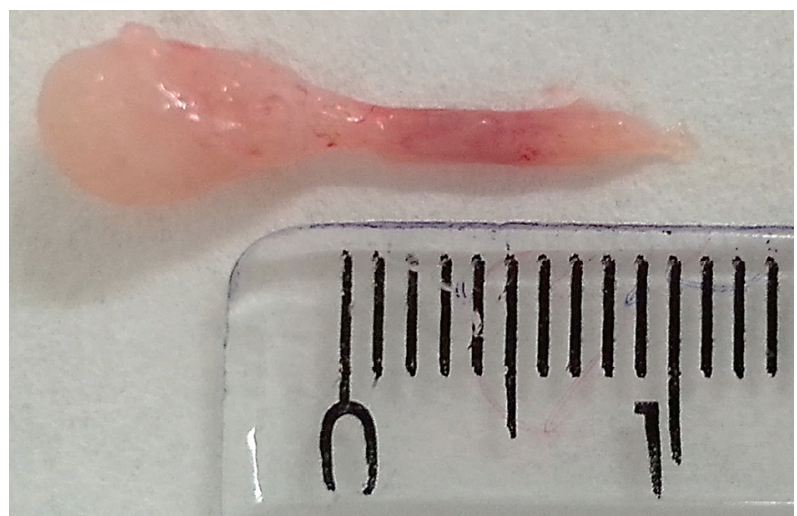


Com a rata em decúbito dorsal, por meio de incisão em "Y" invertido, iniciada no primeiro terço caudal da linha mediana do abdome e na altura da sínfise púbica, bifurcando-se para a face interna das coxas, é possível observar as estruturas que compõe o trato genito-urinário. A uretra atravessa quase adjacentemente a sínfise púbica e é separada por uma pequena quantidade de tecido adiposo. A seguir, a pele dos animais é rebatida para expor a porção caudal da parede ventro-anterior do abdome, da região inguinal, das faces internas e posteriores das coxas e da genitália externa para remoção do tecido conjuntivo fibroadiposo da região ventral abdominal, inguinal e perigenital até a face posterior das coxas. É feita a dissecação fina da uretra (ventral) e da vagina (dorsal) em conjunto com a remoção do tecido conjuntivo e exposição da túnica muscular superficial desses órgãos e remoção do óstio vaginal. A uretra e a vagina são retiradas em monobloco por meio de secção na porção mais cranial possível junto à sínfise púbica (Figura 14).

Figura 14 - Anatomia da pelve feminina de rata
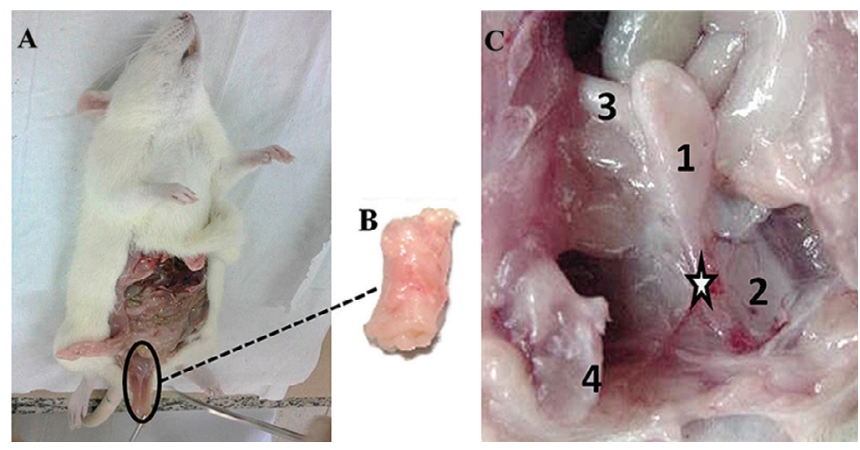

(A) e (B) retirada do conjunto uretra-vagina; (C) visão interna: bexiga (1), vagina (2), cornos uterinos (3), sínfise púbica (4) e uretra (牴) 


\section{Estrutura da uretra}

Por meio de cortes transversais corados com Hematoxilina-eosina (HE), é possível observar a morfologia geral da uretra normal (Figura 15).

A uretra apresenta luz irregular parcialmente colabada, constituída por várias pregas de mucosa formada por epitélio estratificado pavimentoso e lâmina própria/ submucosa de tecido conjuntivo frouxo. Duas camadas de músculo liso envolvem as túnicas mucosa e submucosa, sendo uma com orientação longitudinal (interna), e outra, circular (externa). Em vários pontos, um entrelaçamento dessas camadas é observado. Mais externamente, uma camada de fibras musculares estriadas, orientada circularmente, circunscreve a uretra ao longo de toda sua extensão. Essa camada denomina-se músculo uretral externo. Entre as camadas de músculo liso e estriado está presente um plexo vascular.

Figura 15 - Micrografia do corte transversal da uretra de ratas corada em HE

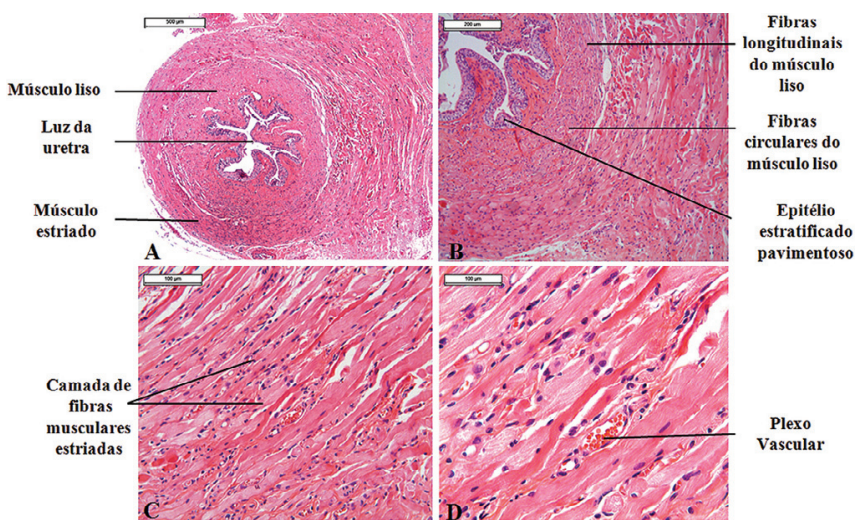

(A) aumento de 4x; (B) aumento de 10x; (C) aumento de 20x; (D) aumento de 40x 
A coloração de Tricômico de Masson mostra simultaneamente as fibras musculares lisas e estriadas (em vermelho) e fibras de colágeno (em azul) uretral (Figura 16).

Figura 16-Micrografia do corte transversal da uretra de ratas corada com Tricômico de Masson

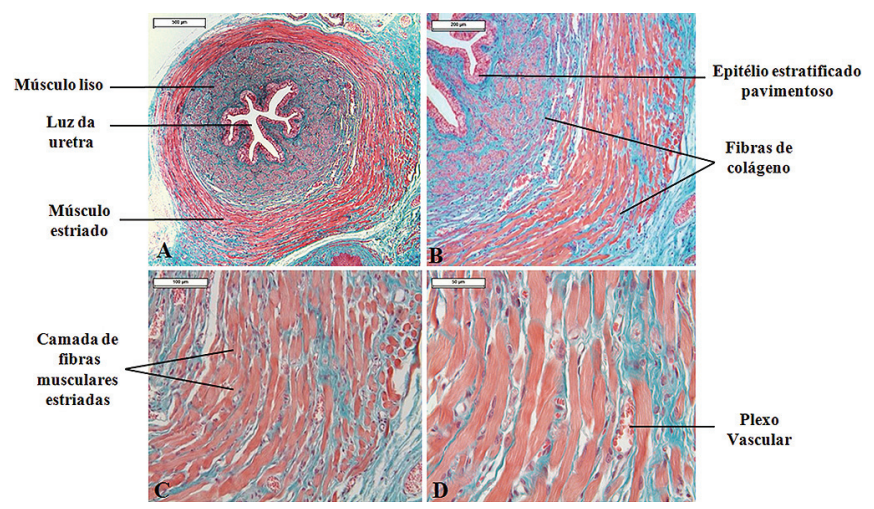

(A) aumento de 4x; (B) aumento de 10x; (C) aumento de 20x; (D) aumento de 40x

Por meio da coloração de Picrosirirus Red (Figura 17), obtém-se a confirmação da quantidade de colágeno presente entre as fibras musculares da uretra, sejam elas lisas sejam estriadas. Essa coloração, juntamente com a Reticulina de Gomori (Figura 18), confirma a presença de colágeno e torna possível identificá-lo em fibras de colágeno tipo I e III. 
Figura 17 - Micrografia do corte transversal da uretra de ratas corada com Picrosirius Red

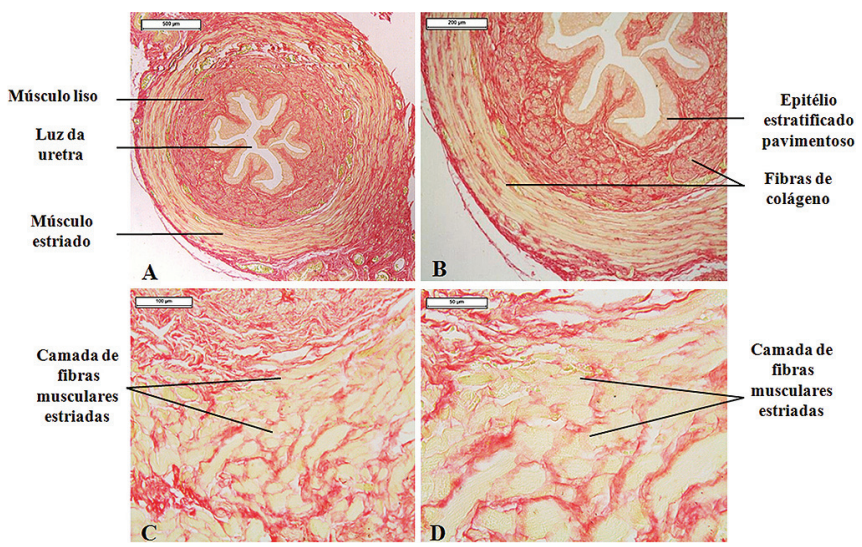

(A) aumento de 4x; (B) aumento de 10x; (C) aumento de 20x; (D) aumento de $40 \mathrm{x}$

Figura 18. Micrografia do corte transversal da uretra de ratas corada com Reticulina de Gomori

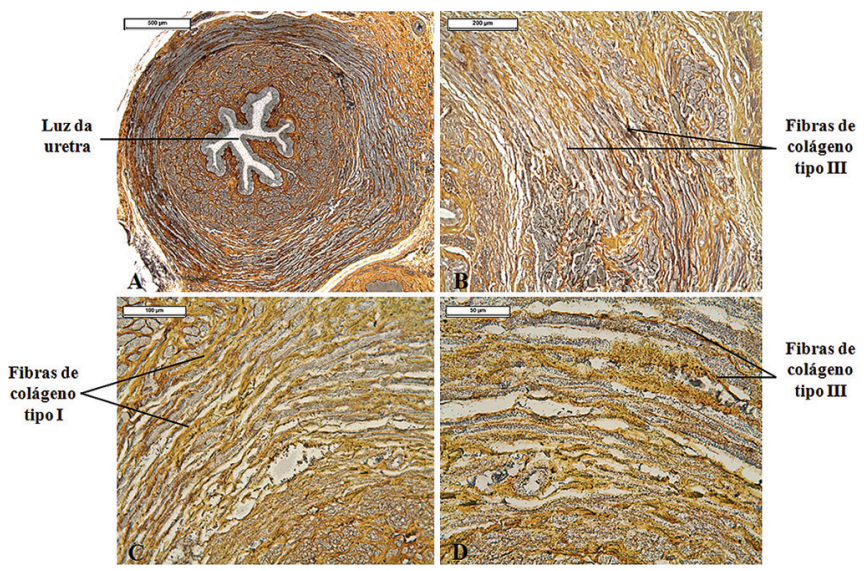

(A) aumento de 4x; (B) aumento de 10x; (C) aumento de 20x; (D) aumento de $40 \mathrm{x}$ 
A análise dos açúcares neutros presentes nas glicoproteínas das membranas basais das fibras musculares da uretra pode ser feita através da coloração de PAS, que ainda permite destacar o endomísio das fibras musculares (Figura 19).

Figura 19-Micrografia do corte transversal da uretra de ratas corada com PAS

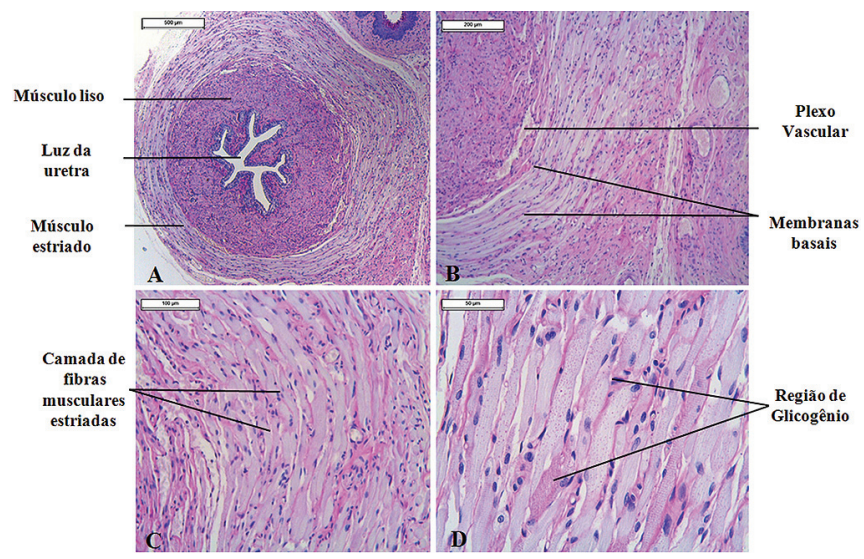

(A) aumento de 4x; (B) aumento de 10x; (C) aumento de 20x; (D) aumento de $40 \mathrm{x}$

A coloração de azul de toluidina evidencia a presença de glicosaminoglicanos sulfatados e carboxilados e, no caso da figura abaixo, evidenciou discreta quantidade desses polissacarídeos na membrana basal das fibras musculares uretrais (Figura 20). 
Figura 20 - Micrografia do corte transversal da uretra de ratas corada com Azul de Toluidina

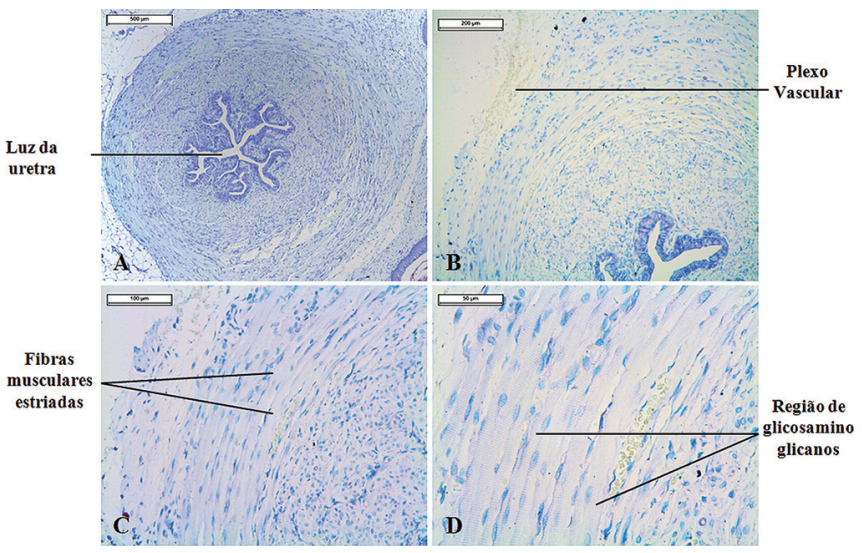

(A) aumento de 4x; (B) aumento de 10x; (C) aumento de 20x; (D) aumento de $40 \mathrm{x}$

\section{Ultraestrutura da uretra}

A análise ultraestrutural do músculo estriado uretral por meio da microscopia eletrônica de transmissão revela miofibrilas bem organizadas formando sarcômeros íntegros com características morfológicas relacionadas aos diferentes tipos musculares. Mitocôndrias intermiofibrilares e raras gotículas de lipídeos são observadas. Não é detectado aumento do conjuntivo intersticial e há pouco colágeno entre as miofibrilas. São observados grânulos de glicogênio dispersos, subsarcolemais e intermiofibrilares (Figura 21). 
Figura 21 - Micrografia eletrônica do músculo estriado uretral de ratas
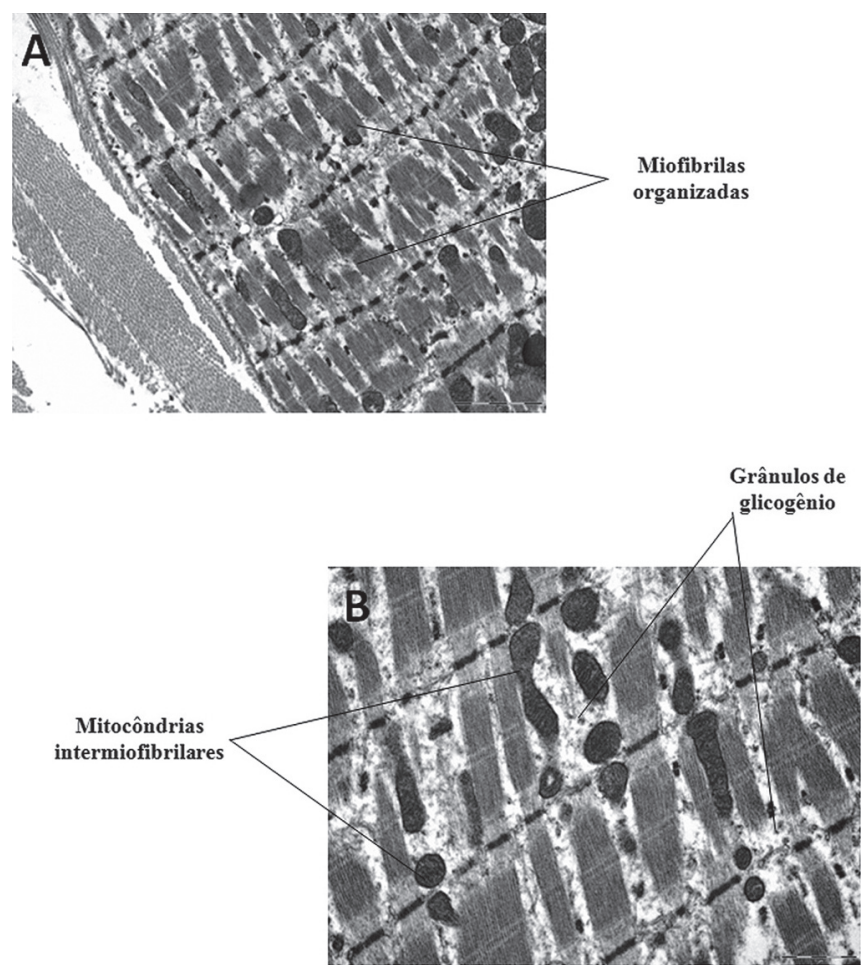

\section{Imunoistoquímica: anticorpos para miosina rápida e lenta}

As reações de imunoistoquímica revelam que as miofibrilas do músculo estriado expressam predominantemente as cadeias de miosina pesada rápida. As camadas de fibras rápidas estão presentes em uma camada externa espessa, em toda a circunferência. As fibras lentas apresentam-se em uma camada interna delgada, com fibras individuais pequenas e finas (Figura 22). 
Figura 22 - Micrografias do corte transversal da uretra de ratas após imunoistoquímica para fibras rápidas $(\mathrm{A}$ e $\mathrm{C})$ e lentas $(\mathrm{B}$ e D)
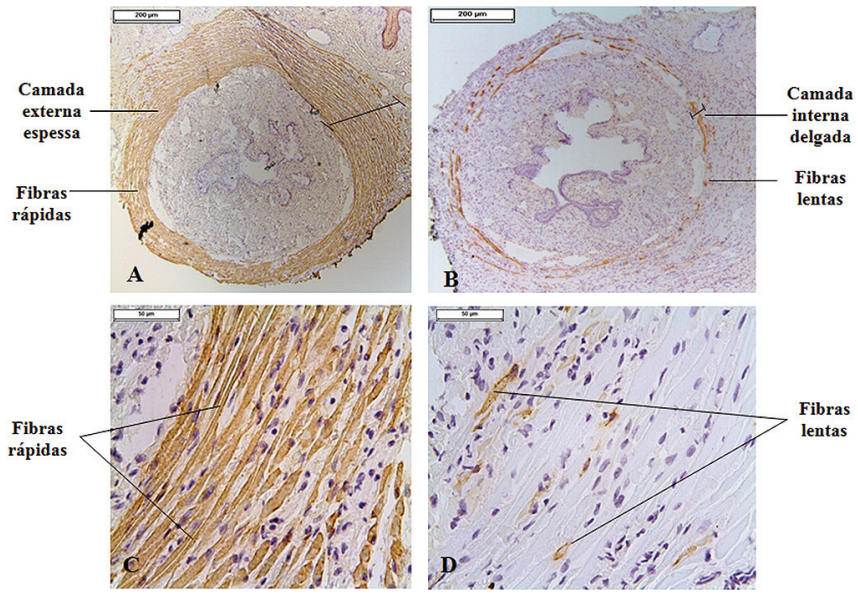

(A) e (B) aumento de 4x; (C) e (D) aumento de 40x 


\section{Considerações finAIS}

O conteúdo deste guia ilustrado não apenas pode facilitar o entendimento das estruturas que compõem a uretra, como também pode servir de modelo para a reprodutibilidade das técnicas e análises com finalidade científica. 


\section{REFERÊNCIAS}

ATTIAS, M. Microscopia eletrônica em Biologia. Disponível em: <http://www.cbpf.br/ emecbpf/MET_Biologia_ Attias.pdf $>$. Acesso em: 7 out. 2014.

BOZZOLA, J. J.; RUSSELL, L. D. Ultramicrotomy. In: Electron microscopy: principles and techniques for biologists. 2.ed. Sudbury (MA): Jones and Bartlett Publishers, 1999. p.72-119.

JUNQUEIRA, L. C. U.; JUNQUEIRA, L. M. M. S. Técnicas básicas de citologia e histologia. São Paulo: Santos Editora, 1983.

JUNQUEIRA, L. C.; CARNEIRO, J. Histologia básica. 8.ed. Rio de Janeiro: Guanabara Koogan, 1995.

MARINI, G. et al. Morphological changes in the fast vs. slow fiber profiles of the urethras of diabetic pregnant rats. Urogynaecologia, v.25, n.9, p.31-6, 2011.

RODRIGUES et al. Desenvolvimento de nanocompósitos polipropileno/argila bentonita brasileira: I tratamento da argila e influência de compatibilizantes polares nas propriedades mecânicas. Polímeros: Ciência e Tecnologia, São Carlos, v.17, n.3, p.219-27, 2007.

STEVENS, A.; LOWE, J. Histologia. São Paulo: Manole, 1995. 


\section{Sites consultados}

http://www.dbio.uevora.pt/jaraujo/biocel/mftecnicas.htm http://www.estudodavida.no.comunidades.net/index. php? pagina $=1205862713 \_01$

http://www.icb.usp.br/mol/1basico.html http://www.neurofisiologia.unifesp.br/eletronica.htm http://www.pathology.com.br/instrutoria/introducao\%20 microscopia/introducao_microscopia.html http://www.sciencedirect.com 


\section{SOBRE O LIVRO}

Formato: $12 \times 21 \mathrm{~cm}$

Mancha: $20,4 \times 42,5$ paicas

Tipologia: Horley Old Style 10,5/14

Papel: Off-set $75 \mathrm{~g} / \mathrm{m}^{2}$ (miolo)

Cartão Supremo $250 \mathrm{~g} / \mathrm{m}^{2}$ (capa)

1a edição: 2015

EQUIPE DE REALIZAÇÃO

Coordenação Geral

Marcos Keith Takahashi 